Gut, 1972, 13, 95-98

\title{
Intestinal absorption of an arginine-containing peptide in cystinuria
}

\author{
A. M. ASATOOR, B. D. W. HARRISON, M. D. Milne, AND D. I. PROSSER
}

From the Medical Unit, Westminster Medical School, London

SUMMARY Separate tolerance tests involving oral intake of the dipeptide, L-arginyl-L-aspartate, and of a corresponding free amino acid mixture, were carried out in a single type 2 cystinuric patient. Absorption of aspartate was within normal limits, whilst that of arginine was normal after the peptide but considerably reduced after the amino acid mixture. The results are compared with the increments of serum arginine found in eight normal subjects after the oral intake of the free amino acid mixture.

Analyses of urinary pyrrolidine and of tetramethylenediamine in urine samples obtained after the two tolerance tests in the patient support the view that arginine absorption was subnormal after the amino acid mixture but within normal limits after the dipeptide.

The products of protein digestion within the gut lumen are absorbed by two separate processes: active transport of free amino acids, and mucosal uptake of oligopeptides followed by their hydrolysis to free amino acids which are subsequently transported to the capillary portal blood. There is now considerable evidence that in Hartnup disease (Navab and Asatoor, 1970; Asatoor, Cheng, Edwards, Lant, Matthews, Milne, Navab, and Richards, 1970), despite a grossly reduced active transport of many free amino acids, mucosal uptake of oligopeptides is within normal limits. Corresponding evidence in the closely allied disease, cystinuria, is less complete. Hellier, Perrett, and Holdsworth (1970), using an isolated jejunal loop technique, showed that uptake of lysine from the dipeptide glycyl-lysine in a single cystinuric patient was more rapid than from a corresponding mixture of the two free amino acids. Asatoor, Crouchman, Harrison, Light, Loughridge, Milne, and Richards (1971), using the oral tolerance method, found that there was no difference in the rate of lysine absorption in three cystinuric patients after oral ingestion of lysyl-glycine and of the equivalent free amino acids. Further observations using a casein meal suggested that use of an arginine-containing peptide would be more likely to give differing results in the two separate tolerance tests than if oligopeptides containing lysine were used. Owing to the reactivity of the guanidino group in the molecule, arginine

Received for publication 7 December 1971. peptides are difficult to prepare in pure and bulk supply. This paper presents evidence that arginine absorption by a single cystinuric patient was more rapid and complete from the dipeptide L-arginyl-Laspartate than from a corresponding amino acid mixture of free arginine and of aspartic acid.

\section{Methods}

The cystinuric patient was an inpatient for assessment of the need for penicillamine therapy to prevent further development of renal calculi. He was a member of a cystinuric family in which children of the affected patients excreted both lysine and cystine in excess, and in the patients there was clear evidence of impaired lysine and arginine absorption from the gut. He was, therefore, a 'type 2' cystinuric by the classification of Rosenberg, Downing, Durant, and Segal (1966). Tolerance tests using an equimolecular mixture of free lysine and of aspartic acid were carried out on the patient and on eight normal control subjects. A pure sample of L-arginylL-aspartate was obtained from commercial sources. The compound was chromatographically pure and after acid hydrolysis produced exactly the expected amounts of free arginine and of aspartic acid. Toxicity tests in rats at 10 times the dosage per kilogram body weight as used in the patient produced no adverse symptoms. It had been planned to repeat the dipeptide tolerance test in a normal control subject, but unfortunately a second batch of this dipeptide obtained from the same commercial 
source was grossly impure and contained no more than $30 \%$ of arginyl-aspartate, the remainder being composed of an unidentified ninhydrin-positive compound. This shows that stringent tests for purity and toxicity on each batch of prepared peptides should always be made before tests of peptide transport are made in man. No adverse symptoms were experienced by the patient after peptide intake, or by the eight subjects after intake of the free amino acid mixture.

Dosage of both the peptide and of the amino acid mixture was $0.09 \mathrm{mmol} / \mathrm{kg}$ body weight, and each was taken by mouth dissolved in $500 \mathrm{ml}$ water in the early morning, fasting state. Blood samples were obtained immediately before the oral dose, and at $15,30,45,60$, and 90 minutes thereafter. Urine specimens from the patient were collected at the following intervals: four hours immediately before the oral dose, $0-4$ hours, 4-8 hours, 8-12 hours, and 12-22 hours after the dose. Similar specimens were not obtained from the controls as it has been previously shown that higher doses of arginine have no effect on urinary amine output in normal man (Asatoor, Lacey, London, and Milne, 1962).

\section{CHEMICAL METHODS}

Amino acids in serum

Ion-exchange chromatography using the Technicon amino acid analyser (Technicon Handbook, 1966).

Heterocyclic amines in urine

The method of Asatoor (1960) and of Asatoor and Kerr (1961) were used.

\section{Diamines in urine}

The procedure was repeated extraction by chloroform from an alkalinized specimen of urine corresponding to one-hour output, followed by transfer to $\mathrm{N} / 10 \mathrm{HCl}$, evaporation to dryness under reduced pressure, and separation by thin-layer chromatography of the residue on silica gel plates (Merck), using butanol : acetic acid : water ; 60:15:25 as developing solvent.

\section{Results}

Figure 1 shows that the rise of serum arginine after ingestion of arginyl-aspartate by the cystinuric patient was considerably higher than after the intake of a corresponding free amino acid mixture. Increments of arginine after the peptide were almost identical with the mean increments of eight normal controls after ingestion of the mixture of arginine and aspartic acid. Aspartic acid is partly absorbed unchanged but a greater proportion is transaminated within the intestinal mucosal cells to

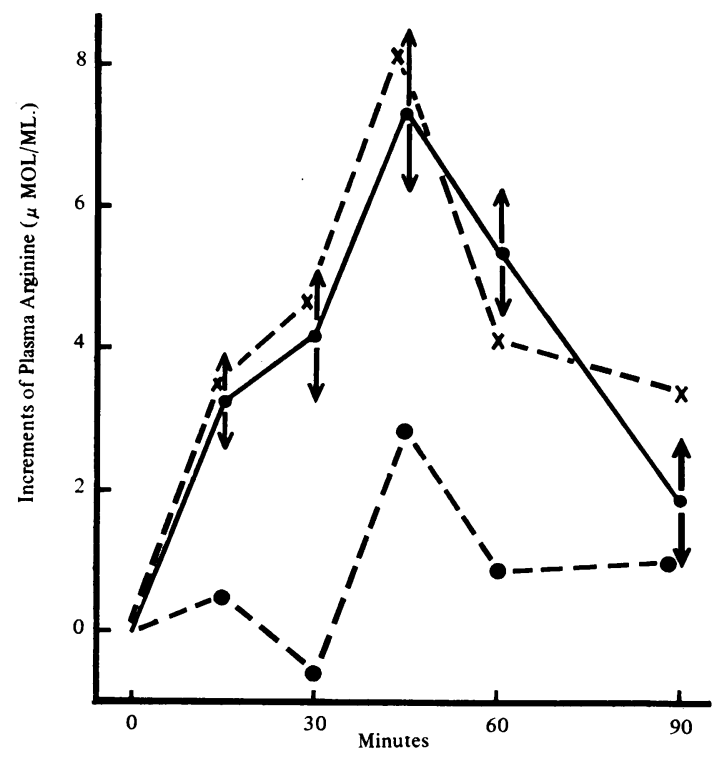

Fig. 1 Increments of plasma arginine in tolerance tests in a cystinuric patient and in eight normal control subjects.

Continuous line: mean of eight normal controls after oral intake of an equimolecular mixture of arginine and aspartic acid. The vertical lines give the standard error of the mean.

Broken line-crosses. Cystinuric after oral intake of L-arginyl-L-aspartate.

Broken line-closed circles. Cystinuric patient after equivalent amino acid mixture.

alanine (Matthews and Wiseman, 1953). Table I shows that increments of serum aspartate plus alanine are almost identical in the cystinuric patient after the peptide and the mixed amino acids, but were somewhat larger than the mean rise in normal controls after the amino acid mixture.

The results of the oral tolerance tests suggest that the cystinuric patient absorbed arginine less efficiently from the free amino acids than from the dipeptide, but that aspartate transport was normal in both cases. This interpretation is supported by analysis of urinary pyrrolidine (Fig. 2). Arginine, which is unabsorbed in the small intestine, is converted by colonic bacteria to pyrrolidine, and this is then partly absorbed and excreted unchanged in the urine (Asatoor et al, 1962). Increase of urinary pyrrolidine is therefore a useful ancillary proof of arginine malabsorption in the small gut. The cystinuric patient investigated had a grossly raised basal pyrrolidine output (Fig. 2), indicating reduced arginine absorption from the amount present in a 


\begin{tabular}{|c|c|c|c|c|c|c|c|c|c|}
\hline \multirow{3}{*}{$\begin{array}{l}\text { Time } \\
(\mathrm{min})\end{array}$} & \multicolumn{6}{|c|}{ Patient } & \multirow{2}{*}{\multicolumn{3}{|c|}{$\frac{\text { Normal Controls (Range and Mean of Eight Subjects) }}{\text { After Mixed Amino Acids }}$}} \\
\hline & \multicolumn{3}{|c|}{ After Peptide } & \multicolumn{3}{|c|}{ After Mixed Amino Acids } & & & \\
\hline & Asp & Ala & $A s p+A l a$ & $A s p$ & Ala & $A s p+A l a$ & Asp & Ala & $A s p+A l a$ \\
\hline 15 & 0.6 & $2 \cdot 4$ & 3.0 & $1 \cdot 2$ & 0.4 & 1.6 & $\begin{array}{l}0.0 \text { to } 1.2 \\
0.5\end{array}$ & $\begin{array}{l}-2.5 \text { to } 0.6 \\
-1.3\end{array}$ & $\begin{array}{l}-2.3 \text { to } 1.6 \\
-0.8\end{array}$ \\
\hline 30 & 0.9 & $3 \cdot 4$ & $4 \cdot 3$ & 0.9 & $2 \cdot 6$ & 3.5 & $\begin{array}{l}-0.6 \text { to } 1.2 \\
0.2\end{array}$ & $\begin{array}{l}-0.2 \\
1.6\end{array}$ & $\begin{array}{l}-0.5 \\
-0.5 \text { to } 4.5 \\
1.8\end{array}$ \\
\hline 45 & $2 \cdot 6$ & $5 \cdot 0$ & $7 \cdot 6$ & $2 \cdot 0$ & $7 \cdot 2$ & $9 \cdot 2$ & $\begin{array}{c}-0.8 \text { to } 1.8 \\
0.2\end{array}$ & $\begin{array}{c}-0.3 \text { to } 7.3 \\
3.0\end{array}$ & $\begin{array}{c}-1 \cdot 1 \text { to } 8.7 \\
3.2\end{array}$ \\
\hline 60 & 0.2 & $2 \cdot 4$ & $2 \cdot 6$ & -0.1 & 0.4 & $0 \cdot 3$ & $\begin{array}{c}0.7 \\
-0.7 \\
0.3\end{array}$ & $\begin{array}{c}-1.0 \\
1.5\end{array}$ & $\begin{array}{c}-1.6 \\
1.8\end{array}$ \\
\hline so & 0.9 & -0.4 & 0.5 & 0.0 & -1.0 & $-1 \cdot 0$ & $\begin{array}{l}-0.9 \text { to } 1.0 \\
-0.1\end{array}$ & $\begin{array}{l}-7.2 \text { to } 0.1 \\
-4.1\end{array}$ & $\begin{array}{l}-7.7 \text { to } 0.8 \\
-4.2\end{array}$ \\
\hline
\end{tabular}

Table Increments of serum aspartate and alanine after oral tolerance tests ( $\mu$ mol/100 ml)

normal diet. After intake of the free amino acid mixture the urinary output of pyrrolidine increased to twice the basal value 12-22 hours after the oral load. The delay is accounted for by the time required for the unabsorbed amino acid to reach the ascending colon. By contrast, after the peptide there was no such rise of pyrrolidine output, indicating that in this case the major part of the ingested arginine had been absorbed in the upper small intestine. There was also a rise in urinary output of putrescine (tetramethylenediamine) in the urinary samples after ingestion of free amino acids but not after the dipeptide. Putrescine could not be detected in the basal specimen, indicating an excretion rate of less than $4 \mu \mathrm{g}$ free base per hour, which is the lowest limit of



Fig. 2 Urinary pyrrolidine output in a cystinuric patient. Continuous line after oral arginine plus aspartic acid. Broken line after arginyl-aspartate. The shaded area gives the limit of excretion in eight normal control subjects, the single horizontal line being the mean output in this group. detection by the method used. In the 12-22-hour specimen, after the free amino acid mixture, the urinary output was $9 \mu \mathrm{g}$ per hour. Putrescine is an intermediate in the bacterial conversion of arginine to pyrrolidine, but after absorption is chiefly oxidized by diamine oxidase, and only a small fraction is excreted in the urine. By contrast, pyrrolidine is the end product of the reaction, and the whole of the amount absorbed is excreted unchanged.

\section{Discussion}

The present results, taken in conjunction with those of a previous paper (Asatoor et al, 1971), indicate that arginine absorption in cystinuric patients is normal or only very slightly reduced from argininecontaining oligopeptides, whereas transport of the free amino acid from the gut lumen is grossly depressed. It is difficult to obtain results which are statistically significant because cystinuria is a somewhat rare disease, and because pure arginine-containing oligopeptides are both expensive and in short supply. The previous results (Asatoor et al, 1971) suggested that tolerance tests using argininecontaining peptides were more likely to give different results in the two separate tolerance tests than corresponding tests using the more readily available peptides containing lysine. Free lysine seems to be absorbed satisfactorily from the gut of cystinuric patients when the amount of the amino acid is either equal to or only slightly above that of a normal protein diet. If, however, very large amounts of free lysine are given by mouth (Milne, Asatoor, Edwards, and Loughridge, 1961), lysine absorption is considerably depressed below that of normal controls. By contrast, transport of free arginine is low in most cystinuric patients both at normal and high concentrations of free arginine within the gut.

It has previously been proved that there is virtually no active transport of free lysine and arginine by intestinal mucosal cells obtained by peroral biopsy 
from most cystinuric patients (McCarthy, Borland, Lynch, Owen, and Tyor, 1964; Thier, Segal, Fox, Blair, and Rosenberg, 1965). Both free arginine and free lysine are readily released from protein chains by the combined action of trypsin and carboxypeptidase B (Dixon and Webb, 1964), and consequently the concentrations of these two amino acids within the gut lumen are higher than that of any of the other amino acids after intake of dietary protein. Thus, Nixon and Mawer (1970) recorded a mean concentration of $700 \mu \mathrm{mol} / 1$ free lysine and 350 $\mu \mathrm{mol} / \mathrm{l}$ free arginine in jejunal aspirates after a milk feed. Obviously, therefore, in absorption of these amino acids from the gut lumen, active transport of the free amino acid as well as mucosal uptake of oligopeptides is probably quantitatively important. Lysine is an essential amino acid in man, whereas arginine is not. Cystinuric patients show no obvious nutritional defeci, adequate absorption of lysine being assured both by uptake of lysine-containing oligopeptides and by some alternative method of transport of the free amino acid other than that of active transport. This alternative method must presumably be either facilitated or passive diffusion. By contrast, the large amounts of arginine released during digestion are inadequately absorbed, accounting for the increased amounts of faecal and urinary pyrrolidine found in many cystinuric patients. Fortunately, on an adequate protein intake, this degree of arginine malabsorption is of no nutritional significance. The results show that the use of urinary pyrrolidine is a more sensitive indicator of reduced arginine absorption than is analysis of tetramethylenediamine (putrescine) in urine samples. Concentrations of the diamine are usually very low because absorbed putrescine is mainly oxidized by diamine oxidase rather than by being eliminated in the urine. The observed concentrations of urinary diamine were similar to those recently reported in cystinuric patients by Bremer, Kohne, and Endres (1971), and the rise after arginine intake suggests that, similarly to pyrrolidine, urinary putrescine in cystinuric patients is chiefly derived from the products of bacterial degradation of unabsorbed arginine within the colon.

The results of this paper would obviously have been more conclusive if it had been possible to carry out the tests on more than a single cystinuric patient, and if the peptide tolerance test could have been carried out in normal controls. In both instances limited supplies of pure peptide prevented these further tests being performed. It is, however, known that arginine absorption in the normal rat is less rapid from arginyl-aspartate than from an equivalent free amino acid mixture (Asatoor et al, 1971), a result the reverse of that found in the patient.

\section{References}

Asatoor, A. M. (1960). Paper chromatography of 2,4-dinitrophenyl derivatives of amines. J. Chromat., 4, 144-152.

Asatoor, A. M., Cheng, B., Edwards, K. D. G., Lant, A. F., Matthews, D. M., Milne, M. D., Navab, F., and Richards, A. J. (1970). Intestinal absorption of two dipeptides in Hartnup disease. Gut, 11, 380-387.

Asatoor, A. M., Crouchman, M. R., Harrison, A. R., Light, F. W., Loughridge, L. W., Milne, M. D., and Richards, A. J. (1971). Intestinal absorption of oligopeptides in cystinuria. Clin. Sci., 41, 23-33.

Asatoor, A. M., and Kerr, D. N. S. (1961). Amines in blood and urine in relation to liver disease. Clin. chim. Acta, 6, 149-156.

Asatoor, A. M., Lacey, B. W., London, D. R., and Milne, M. D. (1962). Aminoacid metabolism in cystinuria. Clin. Sci., 23, 285-304.

Bremer, H. J., Kohne, E., and Endres, W. (1971). The excretion of diamines in human urine. II. Cadaverine, putrescine, 1,3diaminopropane, 2.2'-dithiobis (ethylamine) and spermidine in urine of patients with cystinuria and cystinlysinuria. Clin. chim. Acta, 32, 407-418.

Dixon, M., and Webb, E. C. (1964). Enzymes, 2nd ed. Longmans, London.

Hellier, M. D., Perrett, D., and Holdsworth C. D. (1970). Dipeptide absorption in cystinuria. Brit. med. J. 4, 782-783.

McCarthy, C. F., Borland, J. L., Jr., Lynch, H. J., Jr., Owen, E. E., and Tyor, M. P. (1964). Defective uptake of basic amino acids and L-cystine by intestinal mucosa of patients with cystinuria. J. clin. Invest., 43, 1518-1524.

Matthews, D. M., and Wiseman, G. (1953). Transamination by the small intestine of the rat. J. Physiol. (Lond.), 120, 55P.

Milne, M. D., Asatoor, A. M., Edwards, K. D. G., and Loughridge, L. W. (1961). The intestinal absorption defect in cystinuria. Gut, 2, 323-337.

Navab, F., and Asatoor, A. M. (1970). Studies of intestinal absorption of amino acids and a dipeptide in a case of Hartnup disease. Gut, 11, 373-379.

Nixon, S. E., and Mawer, G. E. (1970). The digestion and absorption of protein in man. 2. The form in which digested protein is absorbed. Brit. J. Nutr., 24, 241-258.

Rosenberg, L. E., Downing, S., Durant, J. L., and Segal, S. (1966) Cystinuria: biochemical evidence for three genetically distinct diseases. J. clin. Invest., 45, 365-371.

Technicon Handbook (1966). Techniques in amino acid analyses, pp. 104-114. Technicon Instrument Co., Chertsey.

Thier, S. O., Segal, S., Fox, M., Blair, A., and Rosenberg. L. E. (1965). Cystinuria: defective intestinal transport of dibasic amino acids and cystine. J. clin. Invest., 44, 442-448. 